Even with these sensitive tests VTEC infection was only demonstrated in some cases.

For the investigation of HUS every effort should be made to detect VTEC infection. However, in cases where VTEC cannot be isolated and no faecal verocytotoxin found alternative tests must be considered. One such test for implicating $E$ coli 0157 is to demonstrate a serum antibody response. Sera from 13 patients with HUS and from whom $E$ coli $\mathrm{O} 157$ had been isolated and 8 healthy controls were examined for antibodies to $E$ coli $\mathrm{O} 157$ antigens by sodium dodecyl sulphate-polyacrylamide gel electrophoresis with immunoblotting. Sera from the patients gave a strong IgM antibody reaction with $E$ coli $\mathrm{O} 157$ lipopolysaccharide (LPS), while control sera did not react with O157 LPS.

Dr Kavi and Dr Rose (May 28, p 1224) raise concern about the validity of using serum antibodies to identify the aetiological infective agent in HUS. Antibody cross-reactions between the $O$-antigens of $E$ coli $\mathrm{O} 157$, Yersinia enterocolitica $(0: 9)$, and Brucella abortus may be possible since the LPS of these bacteria share common sugar sequences. ${ }^{3}$ Indeed antigenic cross-reactions have been demonstrated with bacterial agglutination tests between strains of $B$ abortus and $Y$ enterocolitica $(0: 9), 4,5$ and between $B$ abortus and $E$ coli $0157 .{ }^{6,7}$ On the other hand, $E$ coli $\mathrm{O} 157$ and $Y$ enterocolitica $(0: 9)$ did not cross-react. ${ }^{7,8}$ By immunoblotting we found antibodies in our HUS patients' sera which reacted strongly with the LPS of $B$ abortus but not with the LPS of $Y$ enterocolitica $(0: 9)$, which agrees with Notenboom et al. ${ }^{\text {? }}$

Our studies and the published reports indicate that the major source of antibody cross-reaction is between the LPS of $E$ coli O157 and $B$ abortus, and probably not between $E$ coli $O 157$ and $Y$ enterocolitica. The use of a serological test to implicate a particular microbe as a cause of HUS is inconclusive and serological results should be considered carefully and interpreted in relation to the patient's symptoms.

Division of Enteric Pathogens,

HENRIK CHART

London NW9 5HT
SYLVIA M. SCOTLAND BERNARD ROWE

1. Smith HR, Rowe B, Gross RJ, Fry NK, Scotland SM. Haemorrhagic colins and verocytotoxin-producing Escherichua colh in England and Wales. Lancet 1987; i: $1062-65$.

2. Scotland SM, Rowe B, Smith HR, Willshaw GA, Gross RJ. Vero cytotoxinproducing strams of Eschencha coll from children with haemolvtic uraemic syndrome and their detection by specific DNA probes. F Med Microbiol 1988; 25: syndrom $237-43$.

3. Perry MB, MacLean L, Griffith DW. Structure of the O-chan of the phenol-phase soluble lipopolysacchande of Eschenchia col O:157:H7. Brochem Cell Biol 1986; 64: 21-28

4 Corbeil MJ. The serological relationships between Brucella spp, Yersina enterocoltuca serotype IX and Salmonella serotypes of Kauffmann-Whtte group N. $\mathcal{F}$ Hy Camb 1975, 75: 151-71

5. Lindberg AA, Haeggman S, Karlson K, Carlsson HE. Enzyme immunoassay of the antıbody response to Brucella and Yersinia enterocolitica 09 infections in humans. $\mathcal{F}$ Hyg Camb 1982; 88: 295-307

6. Stuart FA, Corbell MJ. Identufication of a serological cross-reaction between Brucella abortus and Eschernchia coll O157. Vet Rec 1982; 110: 202-03.

7. Notenboom RH, Borczyk A, Karmalı MA, Duncan LMC. Cincal relevance of a serological cross-reaction between Eschenchia coll 0157 and Brucella abortus Lancet 1987; 1i: 744 .

8. Thomas LV, Gross RJ, Cheasty T, Shipp CR, Rowe B. Antigenic relationships among type strains of Yersinia enterocolttica and those of Escherichia coll, Salmonella spp, and Shrgella spp f Clin Microbiol 1983; 17: 109-11.

\title{
PRAZOSIN CONTRAINDICATED IN PATIENTS WITH NARCOLEPSY
}

SIR,-Mignot et $a^{1}$ have demonstrated that central $x_{1}$-adrenoceptors are involved in cataplexy in dogs. Prazosin hydrochloride, a highly selective $\alpha_{1}$-adrenergic receptor antagonist that easily crosses the blood-brain barrier, was found to be a potent cataplexy-inducing agent in narcoleptic dogs. We contacted several sleep centres and, after chart reviews and discussions with sleep disorder specialists, we identified four narcoleptic patients (three in Europe, one in the United States) who had been treated for hypertension with prazosin.

Patient A, a 67-year-old woman, had reported a significant worsening of her cataplexy during a 2 -month period when she was

taking 2 mg prazosin twice daily. Her dosage of clomipramine, a treatment for cataplexy, had been increased to $150 \mathrm{mg}$ daily. For reasons that are unclear, the prazosin was discontinued and replaced by an enzyme-inhibitor-type antihypertensive drug. The ensuing reduction in cataplectic attacks was attributed to better control of the symptoms by clomipramine.

The other three patients were still taking prazosin. Patient B was a 59-year-old man with a history of narcolepsy and cataplexy since the age of 19.24 hour polygraphic monitoring had indicated two sleep onset rapid-eye-movement (REM) periods during spontaneous naps. He had been taking $2 \mathrm{mg}$ prazosin daily since the diagnosis of hypertension 4 years previously.

Patient $\mathrm{C}$ was a 63 -year-old woman who had been diagnosed as having narcolepsy/cataplexy at age 42 , though she had had symptoms since the age of 16 . Nocturnal and nap monitoring indicated sleep onset REM periods. Her hypertension had been diagnosed 12 years earlier and she was taking $4 \mathrm{mg}$ prazosin daily.

We explained that we were investigating the interaction between hypertension and cataplexy, and patients $B$ and $C$ agreed to a 3-week experiment. They recorded cataplectic attacks in a daily log that specified the number, time, duration, and severity of attacks. Severity was characterised as mild (weakness), moderate (involvement of one part of the body, with occasional need to sit), or severe (collapse to the floor). Logs were checked nightly during continuation of current medication (week 1), withdrawal of prazosin (week 2), and resumption of prazosin at the previous dose (week 3 ). Blood pressure was monitored regularly. No drug was withdrawn without the approval of the patient's physician, who could prescribe an enzyme-blocker type of drug at any time if the patient requested a return to antihypertensive medication.

Patient B had 10 attacks per day on average in the baseline week, 3 per day during the prazosin-free week, and 9 per day when prazosin was resumed. Patient $C$ had a baseline mean of 7 daily attacks, a mean of 2 during week 2 , and a mean of 5 daily for week 3 . Patient $C$ reported no "complete" attack (ie, a fall) during the prazosin-free week. Both patients were more impressed by the disappearance of complete attacks than by the reduced number.

Patient D, seen at the University of Michigan Sleep Disorders Center, was a 48-year-old woman with a 3-year history of hypertension and a 2-year history of narcoleptic symptoms, which included daytime somnolence and occasional muscle weakness. She had been treated for 6 months with $4 \mathrm{mg}$ prazosin daily and had noted a sudden worsening of cataplexy within 3 days of the start of that medication. When first seen at the sleep clinic she presented in a state of virtual status cataplecticus, despite treatment by a tricyclic drug. Aware of the research on narcoleptic dogs and prazosin, ${ }^{1}$ the sleep researcher suspected that prazosin was the culprit-and its discontinuation led to spontaneous control of status cataplecticus, although the patient continued to experience intermittent episodes of partial muscle weakness triggered by emotion.

Our observations demonstrate the similarity between canine and human cataplexy and carry a warning against prescribing $\alpha_{1}$-adrenergic antagonists to patients with cataplexy. A survey of 660 narcoleptic patients being followed up in Stanford, California, has revealed that $30 \%$ have hypertension.

Sleep Disorder Clinic,

Stanford University Medical Center,

Stanford, California 94305, USA:

and Hôpital Antoine Béclère,

Clamart, France

CHRISTIAN GUILleminaUlT

Sleep Disorders Clinic

Stanford, Calıfornia

EMMANUEL MigNOT

Sleep Disorders Center,

Unuversity of Michigan,

Ann Arbor

Garches Paris-Ouest

University Hospital

Toulouse Unversity Hospital

Helsinki Unversity Hospital

Michael ALdRICH

Maria-Antonia Quera-Salva

MiCHEL TIBERGE

MarkKu Partinen

1. Mignot E, Gulleminault C, Bowersox S, Rappaport A, Dement WC. Effect of alpha-l-adrenoceptors blockade with prazosin in canme narcolepsy Brain Res 1988; 444: 184.88 